\title{
Random Walk Behavior of Migrating Cortical Interneurons in the Marginal Zone: Time-Lapse Analysis in Flat-Mount Cortex
}

\author{
Daisuke H. Tanaka, ${ }^{1,2}$ Mitsutoshi Yanagida, ${ }^{1}$ Yan Zhu, ${ }^{1}$ Sakae Mikami, ${ }^{3}$ Takashi Nagasawa, ${ }^{3}$ Jun-ichi Miyazaki, ${ }^{4}$ \\ Yuchio Yanagawa, ${ }^{5}$ Kunihiko Obata, ${ }^{6}$ and Fujio Murakami ${ }^{1}$ \\ ${ }^{1}$ Graduate School of Frontier Biosciences, Osaka University, Osaka 565-0871, Japan, ${ }^{2}$ Department of Anatomy, Keio University School of Medicine, Tokyo \\ 160-8582, Japan, ${ }^{3}$ Department of Medical Systems Control, Institute for Frontier Medical Sciences, Kyoto University, Kyoto 606-8507, Japan, ${ }^{4}$ Division of \\ Stem Cell Regulation Research, Osaka University Medical School, Osaka 565-0871, Japan, ${ }^{5}$ Department of Genetic and Behavioral Neuroscience, Gunma \\ University Graduate School of Medicine, Maebashi 371-8511, Japan, and 'Neural Circuit Mechanism Group, Brain Science Institute, RIKEN, Wako 351- \\ 0198, Japan
}

Migrating neurons are thought to travel from their origin near the ventricle to distant territories along stereotypical pathways by detecting environmental cues in the extracellular milieu. Here, we report a novel mode of neuronal migration that challenges this view. We performed long-term, time-lapse imaging of medial ganglionic eminence (MGE)-derived cortical interneurons tangentially migrating in the marginal zone (MZ) in flat-mount cortices. We find that they exhibit a diverse range of behaviors in terms of the rate and direction of migration. Curiously, a predominant population of these neurons repeatedly changes its direction of migration in an unpredictable manner. Trajectories of migration vary from one neuron to another. The migration of individual cells lasts for long periods, sometimes up to $2 \mathrm{~d}$. Theoretical analyses reveal that these behaviors can be modeled by a random walk. Furthermore, MZ cells migrate from the cortical subventricular zone to the cortical plate, transiently accumulating in the MZ. These results suggest that MGE-derived cortical interneurons, once arriving at the $\mathrm{MZ}$, are released from regulation by guidance cues and initiate random walk movement, which potentially contributes to their dispersion throughout the cortex.

Key words: cerebral cortex; GABAergic interneuron; migration; random walk; time-lapse imaging; marginal zone

\section{Introduction}

During development, neurons are thought to migrate from their origin near the ventricle to distant territories by detecting environmental cues in the extracellular milieu, sometimes over long distances. The occurrence of correct migration is crucial for the establishment of CNS cytoarchitectures essential for brain functions. Indeed, defects in migration-related molecules lead to malformations in laminated structures and nuclei (for review, see Gleeson and Walsh, 2000; Walsh, 2000; Rice and Curran, 2001; Wingate, 2001; Marín and Rubenstein, 2003; Bloch-Gallego et al., 2005). These cytoarchitectural defects may consequentially cause brain dysfunctions including mental retardation, epilepsy, and severe learning disabilities (for review, see Walsh, 2000; Ross and Walsh, 2001; ten Donkelaar et al., 2003).

\section{Received Nov. 11, 2008; accepted Dec. 16, 2008.}

This work was supported by Solution Oriented Research for Science and Technology from the Japan Science and Technology Corporation and by grants-in-aid from the Japan Society for the Promotion of Science, the Ministry of Education, Culture, Sports, Science, and Technology Japan, and Takeda Science Foundation. We thank Drs. M. Ueda and J. Takagi for generous advice for random walk analysis, Dr. K. Nishida for pCAG-MCS(-) construct, Dr. R. Y. Tsien for monomeric Cherry construct, Dr. Y. Hatanaka for pCAG-EGFP and pCAG-dsRed2, and Drs. Y. Tanabe and K. Yamauchi for critically reading this manuscript.

Correspondence should be addressed to Fujio Murakami, Graduate School of Frontier Biosciences, Osaka University, Yamadaoka 1-3, Suita, 0saka 565-0871, Japan. E-mail: murakami@fbs.osaka-u.ac.jp.

DOI:10.1523/JNEUROSCI.5446-08.2009

Copyright $\odot 2009$ Society for Neuroscience $\quad$ 0270-6474/09/291300-12\$15.00/0
Although the mechanisms of neuronal migration are not fully understood, in vitro and genetic studies demonstrated that attractive and repulsive cues known to act as axon guidance cues regulate neuronal migration (for review, see Brose and TessierLavigne, 2000; Park et al., 2002; Tamagnone and Comoglio, 2004). Morphologically, the leading edge of migrating neurons is similar to axonal growth cones (for review, see Lambert de Rouvroit and Goffinet, 2001), suggesting that migrating neurons use sensing mechanisms similar to those used by growing axons. Thus, currently the most widely accepted hypothesis argues neuronal migration trajectories depend on the expression patterns of extracellular guidance cues and the subsequent responses by migrating neurons to these cues.

Accumulating evidence indicates that neurochemical as well as neurophysiological properties of individual neurons depend on their spatiotemporal origin (for review, see Cepko, 1999; Jessell, 2000; Marquardt and Gruss, 2002; Shirasaki and Pfaff, 2002). Therefore, one might speculate that neurons migrating from the same spatiotemporal origin should express similar migrating behaviors. Our recent imaging experiments, however, illustrated that cortical interneurons generated in a restricted spatiotemporal origin in the basal forebrain, namely embryonic day 12 (E12) medial ganglionic eminence (MGE), tangentially migrated in many directions within a restricted region of the marginal zone 
(MZ) (Tanaka et al., 2006). A possible explanation for this unexpected finding is that interneurons generated from distinct regions within the MGE (Flames et al., 2007; Wonders et al., 2008) respond distinctly to guidance cues and therefore migrate differently. However, an alternative possibility can also be speculated that migration of $\mathrm{MZ}$ interneurons is not regulated by guidance cues at all, but rather individual interneurons move cellautonomously.

To explore this hypothesis, we tracked the behavior of MGEderived interneurons in the $\mathrm{MZ}$ for $>50 \mathrm{~h}$ in flat-mount cortices and found that these neurons exhibited a diverse range of behaviors both in terms of the rate and direction of migration. We also found that a predominant population of the neurons repeatedly changed their direction of migration within the confines of the MZ. Theoretical analyses revealed that these behaviors could be modeled by a random walk. These findings raise the possibility that guidance cue-independent, cell-autonomous regulation governs the migration of interneurons in the MZ. The random walk movement of cortical interneurons may offer some explanation of cortical interneuron dispersion throughout the cortex.

\section{Materials and Methods}

Animals

GAD67-green fluorescent protein (GFP) knock-in ( $\delta$-neo) mice (GAD67-GFP mice) (Tamamaki et al., 2003) were maintained in an ICR background. CXCL12/GFP knock-in mice (CXCL12-GFP mice) (Ara et al., 2003), mice carrying a floxed Cxcr4 $\left(\right.$ Cxcr $4^{\text {loxP/+ }}$ or Cxcr $4^{\text {loxP/loxP }}$ mice) (Tokoyoda et al., 2004), and CAG-CAT-EGFP reporter mice (Kawamoto et al., 2000) were maintained in a C57B/6 background. At noon on the day of vaginal plug detection was termed as E0.5. E19.5 was defined as postnatal day $0(\mathrm{P} 0)$. All experiments were performed in accordance with the Osaka University Guidelines for the Welfare and Use of Laboratory Animals.

\section{In vivo electroporation}

Ganglionic eminence (GE)-directed exo utero electroporation was performed on E12 wild-type, E12 GAD67-GFP, E12.5 GAD67-GFP, E12.5 CAG-CAT-EGFP, E12.5 Cxcr $4^{\text {loxP/+ }}$, or E12.5 Cxcr $4^{\text {loxP/loxP }}$ embryos as described previously (Tanaka et al., 2006) with minor modifications. In brief, the uterine wall was removed, an $\sim 1 \mu$ l plasmid solution was injected into the lateral ventricle, the head was clasped with a pair of electrodes (CUY650P2 or CUY650P3; Unique Medical Imada) at an angle of $30-60^{\circ}$ from the horizontal plane, and electric pulses ( $30 \mathrm{~V}$ for 50 $\mathrm{ms}$, five times in $950 \mathrm{~ms}$ intervals) were delivered. Plasmids were dissolved in PBS $(0.1 \mathrm{M}, \mathrm{pH} 7.4)$ and used at the following final concentrations: $0.5 \mu \mathrm{g} / \mu \mathrm{l}$ pCAG-EGFP (Niwa et al., 1991; Hatanaka et al., 2004) for a single application or $1 \mu \mathrm{g} / \mu \mathrm{l}$ when mixed with other plasmids; $0.5-1$ $\mu \mathrm{g} / \mu \mathrm{l}$ pCAG-DsRed2 (Hatanaka et al., 2004); $0.25 \mu \mathrm{g} / \mu \mathrm{l}$ pCAG-Cre; and $1 \mu \mathrm{g} / \mu \mathrm{l} \mathrm{pCAG-MCS}(-)$-monomeric Cherry (pCAG-mCherry) (Shaner et al., 2004). Hereafter, an animal that was subjected to electroporation of plasmid $\mathrm{xx}$ to the GE on embryonic day yy and was examined at embryonic or postnatal day zz will be termed as $x x /$ EyyGe:Ezz or $x x /$ EyyGe:Pzz, respectively.

GE-directed in utero electroporation was performed similarly to GEdirected exo utero electroporation with minor modifications. In brief, a $2-3 \mu \mathrm{l}$ solution of $0.5 \mu \mathrm{g} / \mu \mathrm{l}$ pCAG-mCherry or $0.5 \mu \mathrm{g} / \mu \mathrm{l}$ pCAG-DsRed 2 was injected into the lateral ventricle of E15 GAD67-GFP embryos without removing the uterine wall. Electric pulses $(80 \mathrm{~V}$ for $50 \mathrm{~ms}$, 5 times in $200 \mathrm{~ms}$ intervals) were delivered with a pair of electrodes (CUY650P3; Unique Medical Imada).

Neocortex-directed in utero electroporation was performed on E14 GAD67-GFP embryos as described previously (Hatanaka et al., 2004) with minor modifications. In brief, an $\sim 1 \mu$ l mixture of pCAG-DsRed2 at final concentrations of 0.15 and $1 \mu \mathrm{g} / \mu \mathrm{l}$ pCAG-MCS $(-)$-Cxcl12 was injected into the lateral ventricle, the head was clasped with electrodes (CUY650P5; Unique Medical Imada) horizontally, and electric pulses
(50 $\mathrm{V}$ for $50 \mathrm{~ms}$, five times in $100 \mathrm{~ms}$ intervals) were delivered. As a negative control, pCAG mock vector $(1 \mu \mathrm{g} / \mu \mathrm{l})$ was used.

\section{Fixation of electroporated brains}

Embryos (E14-E19.5) or neonates (P0-P2) were decapitated. The brains were dissected out and immersion fixed in $4 \%$ paraformaldehyde (PFA) in phosphate buffer ( $\mathrm{PB} ; 0.1 \mathrm{M}, \mathrm{pH} 7.4$ ) overnight at $4^{\circ} \mathrm{C}$. DsRed/ E15Ge:P1 neonates were perfused transcardially with 4\% PFA in PB, and the brains were removed and postfixed for $2 \mathrm{~h}$ in the same fixative at $4^{\circ} \mathrm{C}$. All neonates were chilled on ice before decapitation or perfusion.

P7 or P21 mice were deeply anesthetized with sodium pentobarbitone (100-200 mg/kg body weight; Nembutal; Abbott) before perfusion. They were then perfused transcardially with $4 \%$ PFA in PB. The brains were removed and postfixed for $2 \mathrm{~h}$ to overnight in the same fixative at $4^{\circ} \mathrm{C}$.

\section{Time-lapse imaging of flat-mount cortices}

Time-lapse imaging of labeled cells in flat-mount cortices was performed as described previously (Tanaka et al., 2006) with minor modifications. The area of the imaging field was $635 \times 635 \mu \mathrm{m}$ and located around the center of the cortical explant $(\sim 2 \times \sim 3 \mathrm{~mm})$.

Imaging of early-born cells. In brief, Gfp/E12Ge:E15.5 wild-type or DsRed/E12Ge:E15.5 GAD67-GFP neocortices were dissected, flat mounted on collagen-coated membrane inserts with the ventricular side down, covered with a thin layer of collagen gel, and transferred to an incubation chamber $\left(5 \% \mathrm{CO}_{2} / 95 \% \mathrm{O}_{2}\right.$ at $\left.37^{\circ} \mathrm{C}\right)$ filled with supplemented Opti-MEM (Tanaka et al., 2006). Images of labeled cells were collected with a confocal microscope (MRC-1024; Bio-Rad) using a $488 \mathrm{~nm}$ excitation wavelength and 504.5-539.5 nm emission bandpass filter for GFP or a $568 \mathrm{~nm}$ excitation wavelength and $585 \mathrm{~nm}$ emission long-pass filter for DsRed. Images were taken $0-100 \mu \mathrm{m}$ from the tissue surface at 20 or $30 \mathrm{~min}$ intervals. A stack of images was created from a series of consecutive images taken along the $z$-axis at 14 or $15 \mu \mathrm{m}$ intervals at each time point to assemble movies. The movies were used to quantitatively analyze the migratory behaviors.

Imaging of late-born cells. GE-directed in utero electroporation into E15 embryos occasionally caused labeling of the cortical ventribular zone (VZ). In some preparations, projection neuron-like cells were also labeled near the corticostriatal boundary. However, there were clear differences in morphology, location, and density of labeling between projection neurons and interneurons. To avoid contamination by projection neurons, the lateral part of the cortex was excluded from analysis.

Time-lapse imaging methods for late-born cells were essentially the same as those for early-born cells, except that an inverted microscope was used for these experiments. In brief, mCherry or DsRed/E15Ge:P1 GAD67-GFP mice neocortices were dissected, flat mounted on a membrane insert with the ventricular side up, and transferred to a glassbottom dish (35 mm FluoroDish; WPI) filled with supplemented OptiMEM. They were then transferred to an incubation chamber $\left(5 \% \mathrm{CO}_{2} /\right.$ $95 \% \mathrm{O}_{2}$ at $37^{\circ} \mathrm{C}$ ) and fitted onto an inverted microscope stage (IX81; Olympus). Images of labeled cells were taken at $0-70 \mu \mathrm{m}$ from the tissue surface at $20 \mathrm{~min}$ intervals and collected through a $20 \times, 0.45$ numerical aperture objective with a confocal microscope (FV1000; Olympus). Four hundred eighty-eight nanometer excitation wavelength and 505-525 nm emission bandpass filters were used for GFP, whereas $543 \mathrm{~nm}$ excitation wavelength and $560 \mathrm{~nm}$ emission long-pass filters were used for mCherry and DsRed. A stack of images was created from a series of consecutive images for mCherry or DsRed taken along the $z$-axis at $10 \mu \mathrm{m}$ intervals at every time point to assemble movies.

\section{Immunohistochemistry}

Fixed brains were cryoprotected by immersion in 30\% sucrose and cut coronally at $20 \mu \mathrm{m}$. The sections were mounted on slides and washed with PBS. The sections were then incubated in PBS with 0.3\% Triton $\mathrm{X}-100$ and $5 \%$ normal goat serum (NGS) or normal donkey serum (NDS) for $1 \mathrm{~h}$ at room temperature (RT). This was followed by incubation in the primary antibody diluted in PBS with $0.3 \%$ Triton X-100 and either $1 \%$ NGS or NDS for $2 \mathrm{~h}$ at RT or overnight at $4^{\circ} \mathrm{C}$. The primary antibodies used were as follows: rat anti-GFP (1:1000; Nacalai Tesque), rabbit anti-DsRed (1:300; Clontech), rabbit anti-laminin (1:500; Sigma), 
rabbit anti-Cre (1:3000; Novagen), and goat anti-CXCR4 (1:500; Abcam). The sections were incubated for $1 \mathrm{~h}$ at RT in the secondary antibody diluted in $1 \%$ NGS or NDS in PBS. The secondary antibodies used were as follows: donkey FITC-conjugated anti-rat IgG (1:100), donkey Cy3-conjugated anti-goat $\operatorname{IgG}(1: 200)$, donkey biotinylated anti-rabbit IgG (1:400), and goat Cy3-congugated anti-rabbit IgG (1: 100) (all from Jackson ImmunoResearch). When the biotinylated secondary antibody was used, an additional $1 \mathrm{~h}$ incubation with Alexa633-conjugated streptavidin (1:200; Invitrogen) at RT was done. For nuclear staining, some sections were incubated in $0.03 \%$ 4,6diamidino-2-phenylindole (DAPI; Nacalai Tesque) or $0.05 \%$ TO-PRO-3 iodide (Invitrogen) in PBS for $1 \mathrm{~h}$ at RT. Images were captured using a CCD camera (AxioCam; Zeiss) attached to an epifluorescence microscope (BX60; Olympus) or by a confocal microscope (TCS SP2 AOBS; Leica Microsystems).

\section{Quantification and statistics}

Zonal distribution. GE-directed in utero electroporation into E15 embryos occasionally caused labeling of the cortical VZ. To exclude contamination of projection neurons, we electroporated $m$ Cherry by using GAD67-GFP mice. Only mCherry and GFP double-positive cells were subjected to zonal distribution analysis in fixed brains.

To quantify the zonal distribution in labeled cells, coronal sections were made. All labeled cells found ventrolateral to the vertical line drawn through the dorsal edge of the cortex and mediodorsal to the corticostriatal boundary were subjected to analysis. For the analysis of embryonic and neonatal brains, coronal sections were obtained from the rostral end to that of the caudal end of the GE; for P7 brains, coronal sections were obtained from the rostral end to that of the caudal end of the corpus callosum; for P21 brains, coronal sections were obtained from the rostral end of the corpus callosum to where the hippocampus reached the ventral end of the telencephalon, caudally. In each brain, at least five sections were obtained at approximately equal intervals. The cortical zones were determined based on the density and orientation of nuclei labeled by DAPI or TOPRO-3 iodide. Statistical analyses were performed using the Mann-Whitney $U$ test.

To quantify the density of GAD67-GFP cells in Cxcl12-transfection experiments, coronal sections were obtained from the middle level along the rostrocaudal axis. In each section, the region where an accumulation of DsRed + cells was found just underneath the MZ at E17.5 or over $40 \mu \mathrm{m}$ from the MZ at E19.5 was analyzed. MetaMorph (version 6.1; Molecular Devices) was used to measure the area of the region. To distinguish a single GAD67-GFP cell from two closely attached cells, the nuclear marker TO-

PRO-3 iodide was used. The number of GAD67-GFP/TO-PRO-3 cells was counted manually. Statistical analyses were performed using the Mann-Whitney $U$ test.

Morphology in fixed flat-mount cortices. The neocortices were dissected from fixed Gfp/E12Ge:E15.5, E11.5Ge:E17.5, or E12Ge:E17.5 brains, flat mounted on slides with the ventricular side down, and coverslipped.

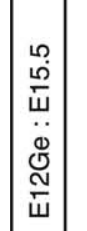

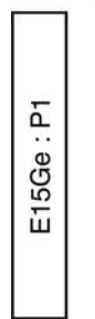

$\mathbf{E}$
B
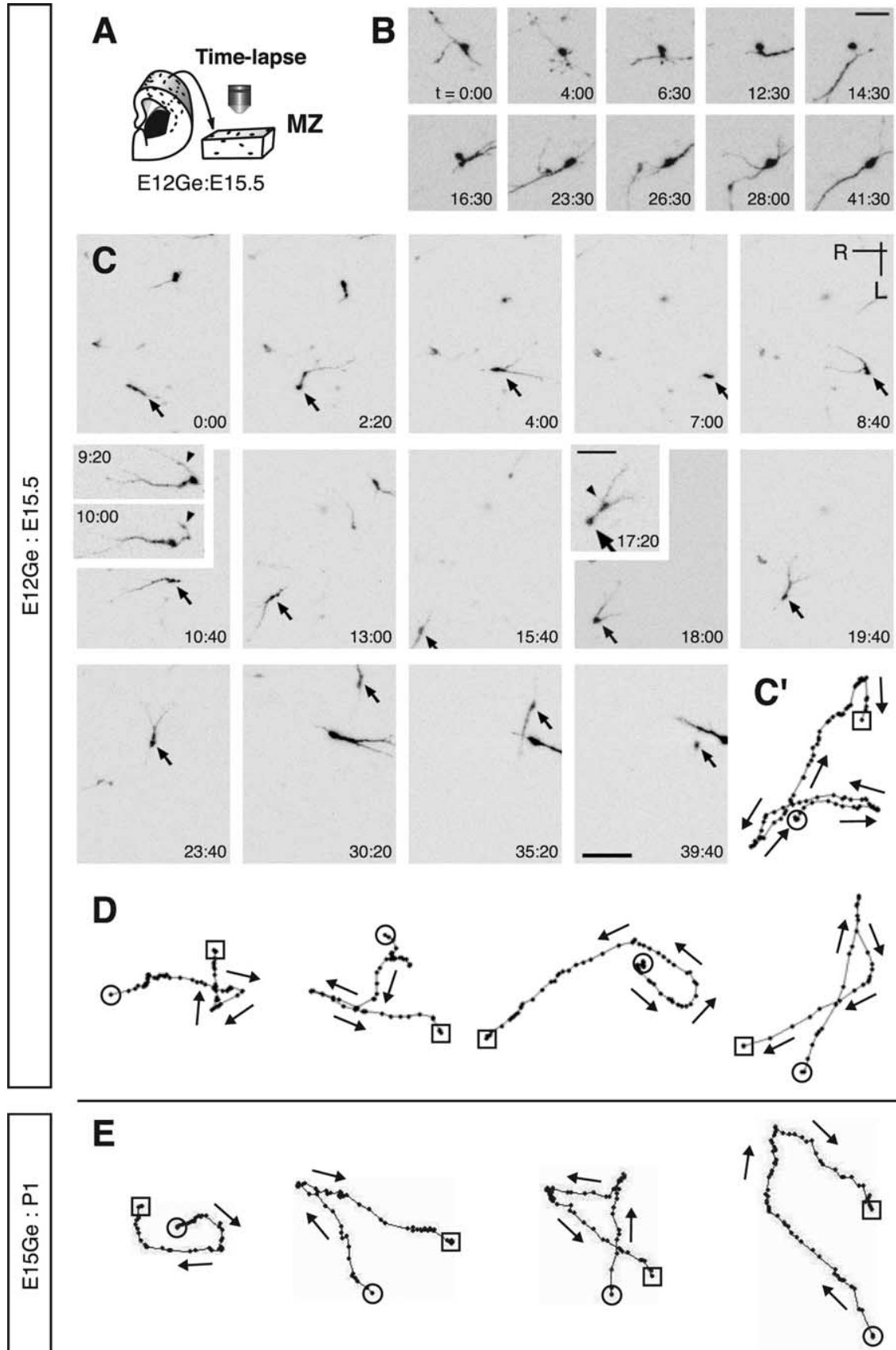

Figure 1. Interneurons exhibit a wide variety of behaviors in the MZ.A, Schematic of time-lapse imaging in a flat-mount cortex from E12Ge:E15.5 brains. B, Time-lapse sequence of a GFP cell showing stationary behavior. Although the soma was stationary, the processes dynamically extended and retracted during the observation period. The numbers in the bottom right corners indicate time. C, Time-lapse sequence of a GFP cell showing wandering behavior. Arrows indicate the same neuron at different time points. In frames 9:20 and 10:00, arrowheads indicates a leading process transforming into a trailing process. In frame 17:20, the arrow or arrowhead indicates a soma or a swelling, respectively. The numbers in the bottom right or top left corners indicate time. $\boldsymbol{C}^{\prime}$, Track of the cell indicated by the arrows in $\mathbf{C}$. Each black dot illustrates the cell position plotted at 20 min intervals. The circle or square illustrates the initial or final position, respectively. Arrows indicate the direction of migration. $\boldsymbol{D}, \boldsymbol{E}$, Examples of cell tracks wandering in E12Ge:E15.5 (D) or E15Ge:P1 (E) cortices. Each black dot illustrates the cell position plotted at 30 min intervals. The circle or square illustrates the initial or final position, respectively. Arrows indicate the direction of migration. R, Rostral; $\mathrm{L}$, lateral. Scale bars: $\boldsymbol{B}, 30 \mu \mathrm{m} ; \boldsymbol{C}-\boldsymbol{E}, 50 \mu \mathrm{m} ; \boldsymbol{C}$ (insets), $25 \mu \mathrm{m}$.

Images were then captured using a confocal microscope (TCS SP2 AOBS). Projection images were constructed from z-stacks for the analysis of morphology. The leading processes of GFP cells that extend one or two processes were subjected to quantitative analysis. The leading process was defined as the thickest process extending from a GFP cell. The orientation of leading processes was defined as that of a line connecting 


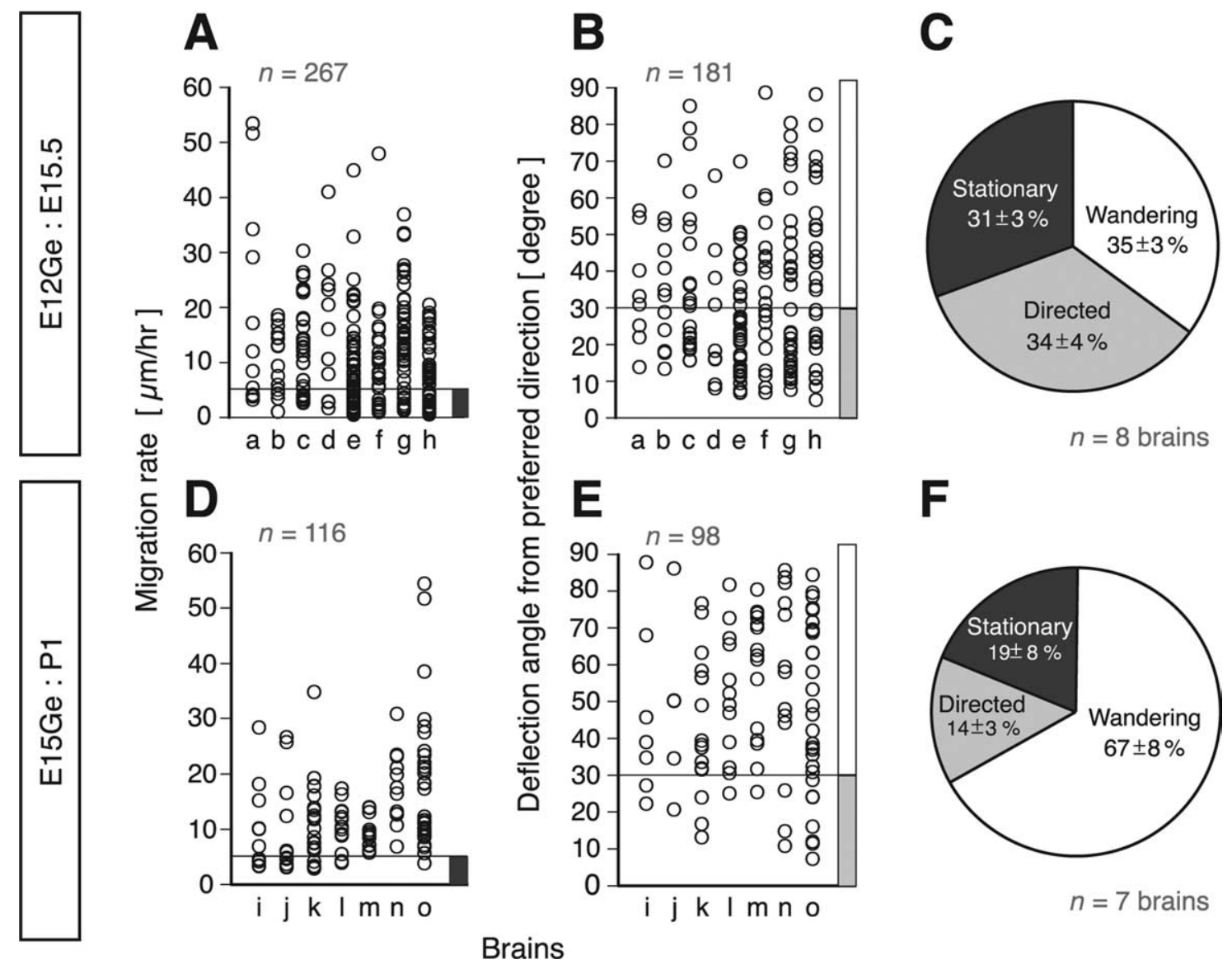

Figure 2. Major population of MZ interneurons are wandering cells. Data are from DsRed cells in E12Ge:E15.5 GAD67-GFP cortices ( $n=1$; $\mathrm{a}$ in the abscissa of $\boldsymbol{A}$ and $\boldsymbol{B}$ ) and GFP cells in E12Ge:E15.5 wild-type cortices $(n=7 ; \boldsymbol{b}$ - $h$ in the abscissa of $\boldsymbol{A}$ and $\boldsymbol{B})(\boldsymbol{A}-\boldsymbol{C})$ or mCherry cells in E15Ge:P1 GAD67-GFP cortices (D-F). $\boldsymbol{A}, \boldsymbol{D}$, The rate of migration of individual cells in E12Ge:E15.5 $(n=267$ cells, 8 brains) (A) and E15Ge:P1 ( $n=116$ cells, 7 brains) (D) cortices. The dark gray bar indicates the range of cells categorized as stationary cells. $\boldsymbol{B}, \boldsymbol{E}$, The deflection angle of individual migrating cells from their preferred directions in E12Ge:E15.5 ( $n=181$ cells, 8 brains) $(\boldsymbol{B})$ and E15Ge:P1 ( $n=98$ cells, 7 brains) $(\boldsymbol{E})$ cortices. The white or light gray bar indicates the range of cells categorized as wandering or directed cells, respectively. $\boldsymbol{C}, \boldsymbol{F}$, The proportion of cells showing a stationary, directed, or wandering behavior in E12Ge:E15.5 ( $n=267$ cells, 8 brains) ( $(\boldsymbol{C})$ and E15Ge:P1 $(n=116$ cells, 7 brains) $(\boldsymbol{F})$ cortices (average \pm SEM).

the cell body center and the base of the leading process. Medial was defined as $0^{\circ}$, and rostral was defined as $90^{\circ}$. The horizontal plane was then subdivided into 12 sectors, and the proportion of cells whose orientation falls into each sector was plotted as a polar diagram. Statistical analyses were performed using the $\chi^{2}$ test.

Migratory behaviors in time-lapse imaging. Migratory behavior and lingering periods in the $\mathrm{MZ}$ were quantified from movies of migrating cells. Samples in which $>10$ labeled cells could be detected in the imaging field at the beginning of imaging were used for analysis. Cells that migrated into or out of the imaging field during imaging were also subjected to analysis. The presence of robustly migrating cells in every sample analyzed confirmed the general health of the tissues. On some occasions, however, migrating cells vanished suddenly or fragmented into pieces during imaging. Because such cells often occurred late into the long-term observation, it is likely this was the effect of damaged preparations. We therefore carefully discarded data acquired after the detection of such cells.

The trajectory of migrating cells was analyzed using MetaMorph software (version 6.1; Molecular Devices).

To evaluate whether MZ cells moved in a random walk, the meansquare displacement (MSD) of all labeled cells was plotted as a function of time as described previously (Gruler and Bultmann, 1984).

The behaviors of MZ cells were classified into three categories: stationary, directed, and wandering. Stationary cells were defined as cells migrating at a rate of $\leq 5 \mu \mathrm{m} / \mathrm{h}$. Wandering cells were those migrating faster than $5 \mu \mathrm{m} / \mathrm{h}$ and with a deflection angle from their preferred directions (see supplemental Fig. 1, available at www.jneurosci.org as supplemental material, for definition of the deflection angle) of $>30^{\circ}$. Cells migrating at $>5 \mu \mathrm{m} / \mathrm{h}$ and with a deflection angle of $\leq 30^{\circ}$ were regarded as directed cells. We chose 30 as the baseline because this angle is far greater than the deflection angle observed for the trajectories of cultured Xenopus spinal neuron growth cones advancing toward a point (Ming et al., 2002). Statistical analyses were performed using the Mann-Whitney $U$ test.

For the analysis of directionality of migrating cells, the horizontal plane was subdivided into 12 sectors, and the proportion of cells with a preferred direction that falls into each sector was scored. Migrating cells were defined as those migrating at rate of $>5 \mu \mathrm{m} / \mathrm{h}$. Preferred direction of migrating GFP cells was plotted as a polar diagram. Statistical analyses were performed using $\chi^{2}$ test.

\section{Results}

MZ interneurons repeatedly change migration direction in a tangential plane

Although in our previous studies we performed time-lapse imaging of GFP cells in the MZ in GAD67-GFP mice (Tanaka et al., 2003, 2006), there were too many cells to track over many hours. To overcome this technical problem, we labeled a smaller number of interneurons by GE-directed electroporation of Gfp or DsRed at E12 (Tanaka et al., 2006) and performed long-term (up to $56 \mathrm{~h}$ ) time-lapse imaging $3.5 \mathrm{~d}$ later (E15.5) (Fig. $1 \mathrm{~A}$ ). Most cortical interneurons labeled in this way have been shown to derive from the MGE (Tanaka et al., 2006). The labeled cells exhibited a wide variety of behaviors in the MZ (supplemental 
Movie 1, available at www.jneurosci.org as supplemental material). These include stationary cells, which showed very low motility (supplemental Movie 1, light blue arrowhead, available at www.jneurosci.org as supplemental material), and those robustly migrating toward a specific direction (supplemental Movie 1, green arrowhead, available at www.jneurosci.org as supplemental material). Stationary cells barely changed their position during imaging, although some of them had processes that dynamically extended and retracted several times (Fig. $1 B$ ). Curiously, we often observed migrating neurons that repeatedly changed migration direction as though they were wandering (supplemental Movie 1, red and magenta arrowheads, available at www.jneurosci. org as supplemental material; Fig. $\left.1 C, C^{\prime}\right)$. Their trajectories were quite diverse and unpredictable (Fig. $\left.1 C^{\prime}, D\right)$. Similar results were obtained in E15Ge:P1 cortices (Fig. $1 E$ ), suggesting that these migratory behaviors persist during cortical development.

Unlike axons with a growth direction that is regulated by an asymmetrical extension of growth cones, neuronal migration changes are the result of extending a new process and switching the leading process to a new one. We often observed branched leading processes with a swelling at the branch point (Fig. 1C, frame 17:20, arrowhead). Formation of such a branch point was followed by a quick advance of the cell soma, resulting in two processes directly emanating from it (Fig. 1C, frames 18:00 and 8:40). One of these extended to govern the direction of cellular migration (Fig. 1C, frame 9:20), whereas the other retracted and sometimes turned into a trailing process (Fig. $1 C$, frame 10:00, arrowhead). When extension of a new leading process occurred, it emanated not only from the leading process but also from the soma. A new process was formed even in the direction opposite to migration, leading to a reversal of migration direction (Fig. $1 C$, frames 4:00-8:40; supplemental Movie 1, available at www.jneurosci.org as supplemental material). Changes in migration direction took place in an unpredictable manner, suggesting that in these migrating neurons, their timing may not be precisely regulated.

\section{Predominance of wandering neurons}

To describe the migratory behaviors of interneurons quantitatively, interneurons were categorized into three types: stationary, directed, and wandering (see Materials and Methods for definition) (Fig. 2). We found that the major population were wandering cells, which made up about one-third of the cells in E12Ge: E15.5 cortices (Fig. 2C) and two-thirds in E15Ge:P1 cortices (Fig. $2 F)(n=267$ cells, 8 brains in E12Ge:E15. 5 cortices; $n=116$ cells, 7 brains in E15Ge:P1). The ratio of cumulative migrating distance to the distance between the starting and end points of an individual cell was $\sim 1$ for directed cells $[1.15 \pm 0.02$ (average \pm SEM), $n=95$ cells, 8 brains in E12Ge:E15.5; $1.24 \pm 0.04, n=18$ cells, 7 brains in E15Ge:P1] but 3-4 for wandering cells [2.79 \pm
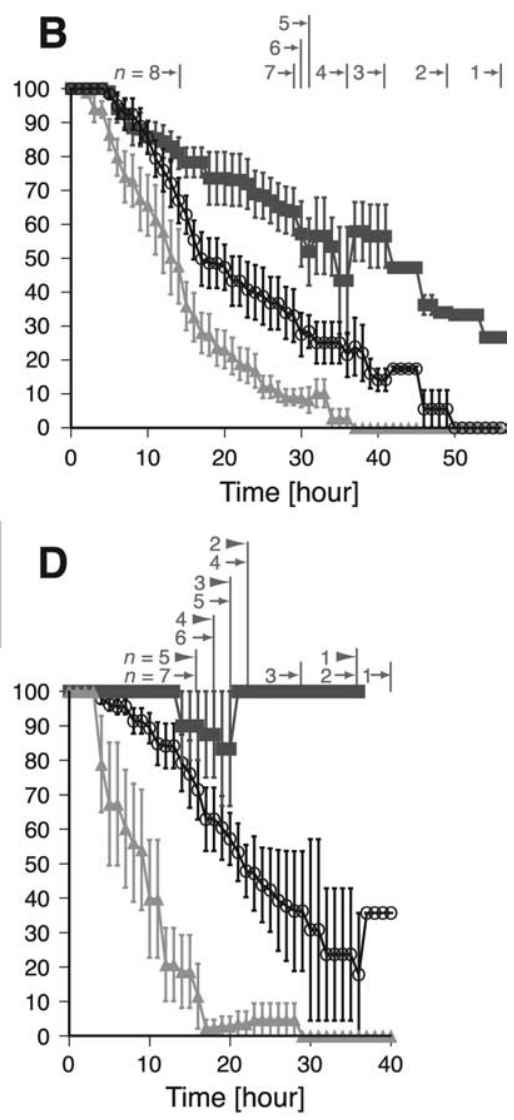

Figure 3. Many interneurons stay in the MZ for a prolonged period of time. The time course of the proportion of labeled cells remaining in the imaging field during time-lapse imaging in E12Ge:E15.5 GAD67-GFP $(n=1)$ and E12Ge:E15.5 wild-type $(n=7)$ cortices $(\boldsymbol{A}, \boldsymbol{B})$ or E15Ge:P1 GAD67-GFP cortices $(\boldsymbol{C}, \boldsymbol{D})$ (average $\pm \mathrm{SEM}$ ) is shown. $\boldsymbol{A}, \boldsymbol{C}$, The data from all labeled cells. Gray 作., in $\boldsymbol{A}$, seven brains were examined analyzed, the number of brains examined for the analysis of stationary cells at a certain period of time is indicated by the gray numbers with closed arrowheads in $\boldsymbol{D}$. The total number of cells analyzed was 99 and 18 for stationary cells, 86 and 80 for wandering cells, and 88 and 18 for directed cells in E12Ge:E15.5 and E15Ge:P1 cortices, respectively.

0.04 ( $p=0.0008$, Mann-Whitney $U$ test $), n=86$ cells, 8 brains in E12Ge:E15.5; $4.16 \pm 0.63(p=0.0017), n=80$ cells, 7 brains in E15Ge:P1], suggesting that wandering cells move inefficiently from one point to another. The population of stationary cells was comparable to that of directed cells (Fig. 2C,F). Thus, the predominant population of MZ interneurons is migrating robustly, alternating the direction of migration in an unpredictable manner. The extent and frequency of the changes in migrating direction varied from one cell to another.

\section{$\mathrm{MZ}$ interneurons linger within the MZ for a long period of time}

Long-term imaging of individual neurons allowed us to estimate the persistence of these behaviors in a tangential plane in the MZ. We analyzed the period of time during which we could observe labeled cells in the imaging field of a confocal microscope $(635 \times$ $635 \mu \mathrm{m})$. Figure $3 A$ shows the results for all labeled cells in E12Ge:E15.5 cortices. Approximately 30\% stayed within the imaging field for over $30 \mathrm{~h}(n=62$ of 198 cells, 6 brains) (Fig. $3 A)$. A similar proportion (26\%) of wandering cells also stayed for over $30 \mathrm{~h}$ ( $n=18$ of 69 cells) (Fig. $3 B)$. A substantial proportion of stationary cells ( $61 \% ; n=39$ of 64 cells) also stayed for over $30 \mathrm{~h}$, whereas only a small proportion of directed cells did $(8 \% ; n=5$ 


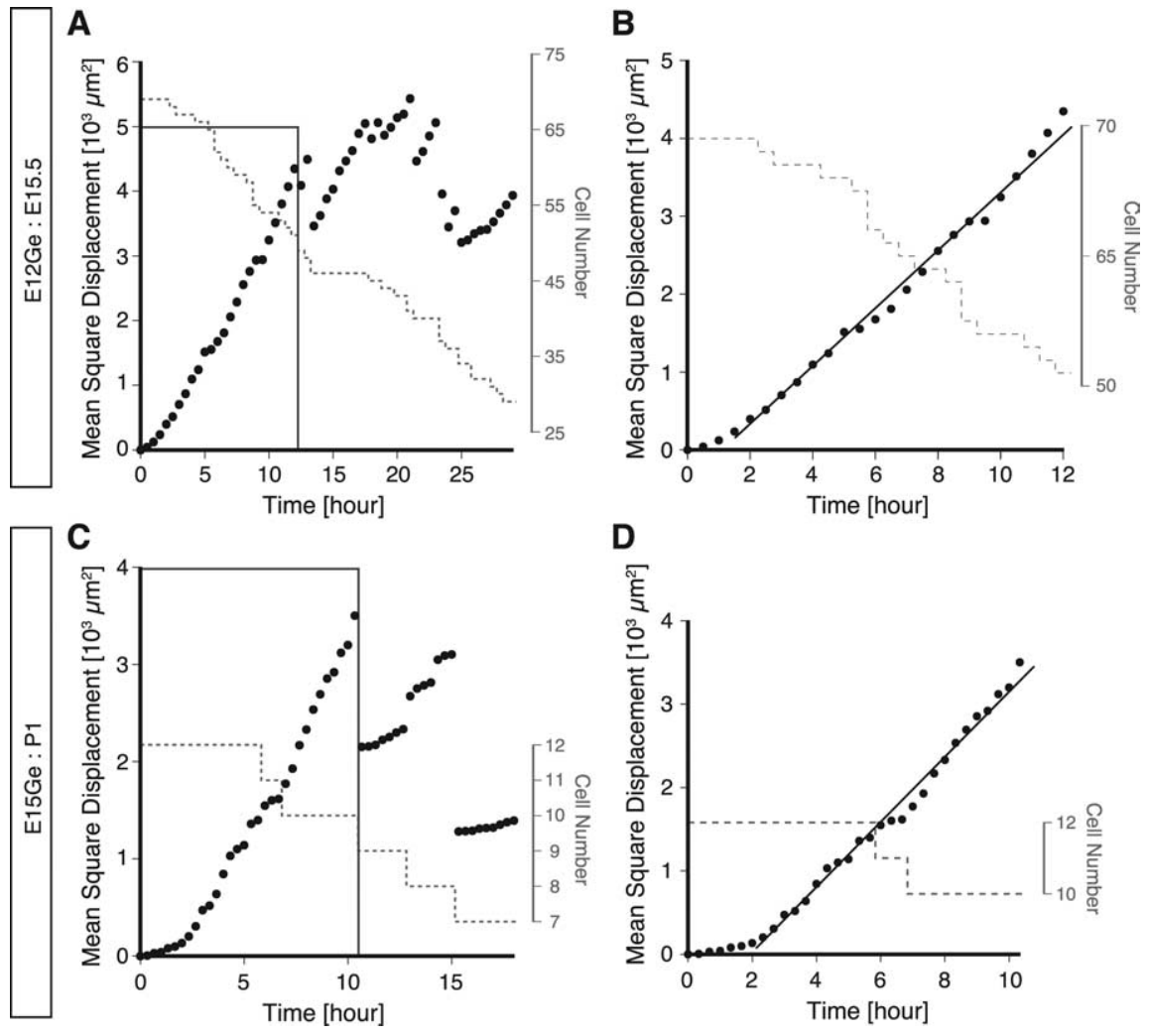

Figure 4. $M Z$ interneurons move in a diffusion mode. $\boldsymbol{A}, \boldsymbol{C}$, Representative data showing the plots of the MSD as a function of time in an E12Ge:E15.5 ( $n=75$ cells) $(\boldsymbol{A})$ and in an E15:P1 ( $n=12$ cells) ( $\boldsymbol{C}$ ) cortex. $\boldsymbol{B}$, Enlarged view of the box in $\boldsymbol{A}$. The approximate linearity was found during time between 2 and $12 \mathrm{~h}$ (black line) despite the cell number decrease (gray dashed line). $\boldsymbol{D}$, Enlarged view of the box in $\boldsymbol{C}$. The approximate linearity was found during time between 2.5 and $10 \mathrm{~h}$ (black line) despite the cell number decrease (gray dashed line). Similar results were obtained from six E12Ge:E15 brains ( $n=252$ cells in total) and seven E15:P1 brains ( $n=116$ cells in total). These results indicate that the behavior of individual neurons can be modeled by a diffusion mode, and it is to be noted that a population of cells composed of neurons each with a directed pattern of migration cannot be explained by the diffusion mode. In $\boldsymbol{B}$ and $\boldsymbol{D}$, the black lines are hand drawn to guide the eye. The MSD show suddenly drops after $\sim 12 \mathrm{~h}$ of imaging. This is likely attributable to the disappearance of some quickly moving cells from the imaging field. Indeed, we found that these drops were always accompanied with the exclusion of high MSD cells from the analysis (Tanaka, M. Yanagida, and Murakami, unpublished observation). along a tangential plane, although the possibility that some interneurons migrate in specific directions cannot be ruled out.

\section{Morphology of MZ interneurons in fixed brains}

We also examined the morphology and orientation of MZ GFP cells in flat-mount cortices that had been fixed immediately after dissection and compared them with the results of time-lapse imaging. The cells in fixed brains exhibited morphologies and orientations similar to those in timelapse imaging: cells with distinct leading process were reminiscent of directed (compare Fig. 5B; supplemental Movie 1, green arrowhead, available at www. jneurosci.org as supplemental material) or wandering (compare Figs. 5C, $1 C$, frame 10:00) cells, and those with a multipolar shape were wandering (compare Figs. $5 F$, $1 C$, frame 7:00) or stationary (compare Figs. 5D-F, $1 B$, frames 28:00 and 4:00, respectively) cells. We also found quantitative similarity; the proportion of cells with one or two processes was comparable with that of the sum of directed and wandering cells, and that of the cells with more than two processes was comparable with that of stationary cells (compare Figs. 5G, 2C). The orientation of GFP cells was random in fixed cortices $\left(\chi^{2}=3.89 ; p>0.97, \chi^{2}\right.$ test) (Fig. $5 A, H$, gray region), as was the case for migrating GFP cells in vitro $\left(\chi^{2}=\right.$ 2.89; $p>0.99)$ (Fig. $5 H$, broken line). These results suggest that in vivo behavior of interneurons is recapitulated in our flatmount preparations. of 65 cells) (Fig. 3B). Similar behaviors were observed for cells in E15Ge:P1 cortices ( $n=116$ cells, 7 brains) (Fig. 3C,D). Because some migrating cells left from or entered the imaging field during the observation period, the data shown in Figure 3 is likely an underestimate of the actual period of the neuron's stay in the MZ. These results suggest that a substantial proportion of interneurons stay in the $\mathrm{MZ}$ for $>1 \mathrm{~d}$.

\section{Random walk behaviors of MZ interneurons}

The unpredictable changes in migration direction of $\mathrm{MZ}$ interneurons together with the striking diversity of behaviors in terms of the rate and the direction of migration led us to hypothesize that MZ interneurons move in a random walk. For particles (neurons) that move in a random walk, the MSD increases linearly as a function of time (Berg, 1993). Therefore, to test this idea that $\mathrm{MZ}$ interneurons move in a random walk, we calculated the MSD for $\mathrm{MZ}$ interneurons and plotted it as a function of time (Gruler and Bultmann, 1984) (Fig. 4A,C). As expected, the MSD increased almost linearly with time (Fig. $4 B, D$, black lines). Although sudden drops in the MSD occurred in late stages of imaging (Fig. $4 A, C$ ), these are ascribable to the disappearance of rapidly migrating cells from the imaging filed (see legend). These results suggest that $\mathrm{MZ}$ interneurons move in a random walk

\section{MZ interneurons appear to migrate \\ from the cortical SVZ and finally settle in the cortical plate} Examination of the changes in the zonal distribution of labeled cells after electroporation suggested that interneurons in the MZ appeared to migrate from the cortical subventricular zone (SVZ) and finally settle in the cortical plate (CP). Two days after electroporation at E12, a stream of labeled cells was observed in the SVZ of the lateral cortex (Fig. 6A,B). Within the cortex, most cells were located in the SVZ, whereas only a small fraction of interneurons were in the MZ (Fig. 6C,F). At E15.5, the proportion of labeled cells in the SVZ decreased, whereas that in the MZ increased (Fig. 6F). At E18.5, the proportion of cells in the SVZ/VZ further decreased, whereas those in the MZ and CP showed an increase (Fig. 6D,F). At this stage, about one-third of labeled cells were found in the MZ (Fig. 6F). From P2 onward, the proportion of cells in the MZ dramatically decreased as labeled cells were predominantly localized in the CP (Fig. 6E,F). Similar results were obtained when electroporation was done at E15. Labeled cells appeared to be translocated from the SVZ to the MZ from E17.5 to P1 but descended to the CP afterward (Fig. 6G).

\section{CXCL12 as an anchoring protein for MZ interneurons}

Results obtained above suggest dispersion of the interneurons takes place in the MZ (Figs. 1-5). A question then arises as to what 
enables them to stay there for a protracted period of time (Fig. 3). Previous studies have shown that CXCL12 and its cognate receptor CXCR4 are expressed in the meninges overlying the $\mathrm{MZ}$ and migrating interneurons, respectively (Stumm et al., 2003; Borrell and Marín, 2006; Paredes et al., 2006; Tiveron et al., 2006) (supplemental Fig. 2, available at www.jneurosci. org as supplemental material), and that CXCL12 can attract interneurons within the cortex (Li et al., 2008; Liapi et al., 2008). To confirm that an interneuron lingering within the $\mathrm{MZ}$ is also regulated by CXCL12/CXCR4 signaling, CXCL12 was ectopically expressed in cortical projection neurons in vivo, and their influence on the distribution of interneurons in the $\mathrm{MZ}$ was examined. We found a higher-density distribution of interneurons near CXCL12expressing cells, suggesting that CXCL12 can attract interneurons within the $\mathrm{MZ}$ (supplemental Fig. 3, available at www. jneurosci.org as supplemental material).

To test the role of CXCR4 expressed by interneurons labeled by our GE-directed electroporation, we next performed interneuron-specific knockdown of CXCR4 by introducing Cre expression plasmids with Gfp into the GE of Cxcr4 $4^{\text {loxP/loxP }}$ embryos (Fig. 7A). We first confirmed that interneurons were specifically labeled, accompanied with highly efficient recombination (supplemental Fig. 4, available at www.jneurosci.org as supplemental material). We found marked downregulation of CXCR4expressing cells in Cxcr $4^{\text {loxP/loxP }}$ cortices $\left[n=44\right.$ of 147 cells $(29 \%)$ in Cxcr $4^{\text {loxP/+ }}$ cortices; $n=10$ of 131 cells (8\%) in Cxcr $4^{\text {loxP/loxP }}$ cortices; four brains for each genotype; $p<0.021$ ] (Fig. $7 B, C$ ), and a significant reduction in the proportion of GFP cells in the MZ, falling from $42 \%$ in Cxcr $4^{\text {loxP/+ }}$ cortices $(n=327$ of 767 cells, 6 brains) (Fig. $7 D, F$, left) to $7 \%$ in Cxcr4 ${ }^{\text {loxP/loxP }}$ cortices $(n=80$ of 1251 cells, 11 brains; $p=0.0009$ ) (Fig. 7E,F, right). These data are in accord with a previous study (Li et al., 2008) and demonstrate that CXCR4 expressed in interneurons themselves labeled by our GE-directed electroporation is required for their accumulation in the $\mathrm{MZ}$.

\section{Discussion}

Time-lapse analysis of the behavior of MGE-derived cortical MZ interneurons in flat-mount preparations demonstrated that they exhibit a diverse range of behaviors in terms of the rate and direction of migration (Figs. 1, 2; supplemental Movie 1 , available at www.jneurosci.org as supplemental material). Most of these neu-
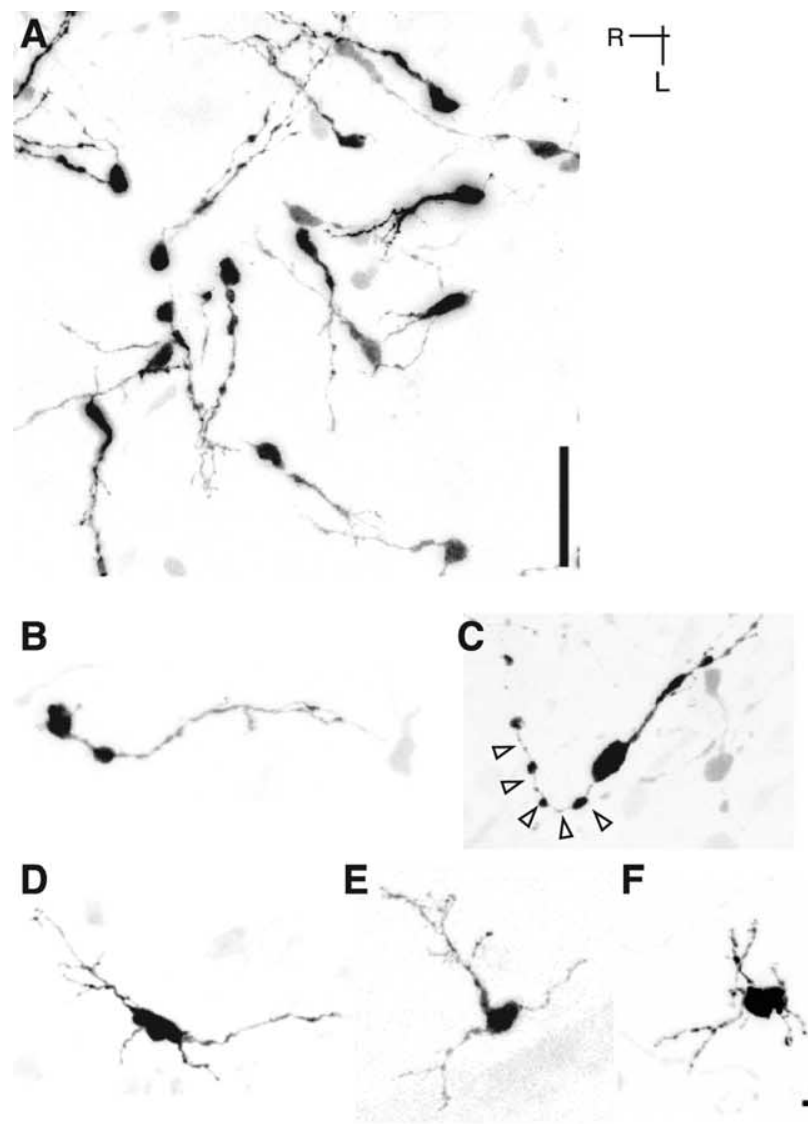

$\mathbf{F}$

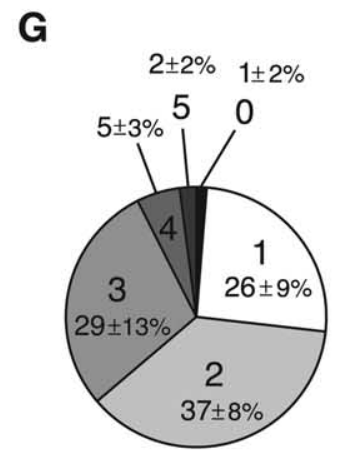

Number of processes
H

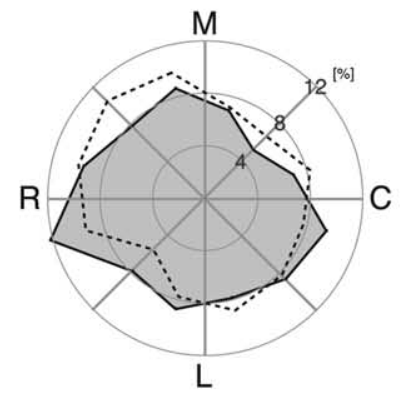

Orientation of leading processes

Direction of migrating neurons in vitro
Figure 5. Morphology and orientation of GFP cells in the MZ in fixed cortices. $A-F$, GFP cell morphology in the MZ in E12Ge: E15.5 (A, B, D, E), E11.5Ge:E17.5 ( $\boldsymbol{C}$, or E12Ge:E17.5 (F) cortices. $\boldsymbol{A}$, GFP cells are oriented in many directions. $\boldsymbol{B}$, A cell with distinct leading process reminiscent of a directed cell. $C$, This cell also has a distinct leading process, but its trailing process is curved (arrowheads), a morphology similar to that of wandering cells in the course of turning (Fig. 1C, frame 10:00). D-F, These cells show a multipolar morphology similar to stationary cells (compare $\boldsymbol{D}-\boldsymbol{F}$, Fig. $1 B$, frames 28:00 and 4:00, respectively). $\boldsymbol{G}$, The proportion of GFP cells with a different number of primary processes in fixed E12Ge:E15.5 cortices ( $n=175$ cells, 6 brains) (average \pm SEM). Digits with large letters, $0-5$, indicate the number of processes. Whereas a majority ( $\sim 60 \%)$ of GFP cells extended one or two processes, one-third of them extended more than three processes. Note that the proportion of cells with one or two processes is comparable with that of the sum of directed and wandering cells (Fig. 20 and that of the cells with more than two processes is comparable with that of stationary cells. $\boldsymbol{H}$, Quantification of the orientation of leading processes of GFP cells in fixed E12Ge:E15.5 cortices (gray region; $n=115$ cells, 6 brains). A similar polar plot of GFP cells migrating in E12Ge:E15.5 cortices in vitro was superimposed for comparison (dashed line; $n=181$ cells, 8 brains). Note the similarity between the two results. The leading processes of GFP cells that extend one or two processes were subjected to the analysis. The leading process was defined as the thickest process extending from a GFP cell. The orientation of leading processes was defined as that of a line connecting the cell body center and the base of the leading process. Medial (M) was defined as $0^{\circ}$, and rostral (R) was defined as $90^{\circ}$. The horizontal plane was then subdivided into 12 sectors, and the proportion of cells with an orientation that falls into each sector was plotted as a polar diagram. For the analysis of the direction of migrating cells in vitro, their preferred migrating cells was defined as those migrating at rate of $>5 \mu \mathrm{m} / \mathrm{h}$. For the analysis of directionality, the horizontal plane was subdivided into 12 sectors, and the proportion of cells with a preferred direction that falls into each sector was scored. The preferred direction of migrating GFP cells (see Materials and Methods) was plotted in the same way as above. L, Lateral.; C, caudal. Scale bars: $\boldsymbol{A}, 40 \mu \mathrm{m} ; \boldsymbol{B}-\boldsymbol{F}, 10 \mu \mathrm{m}$. 


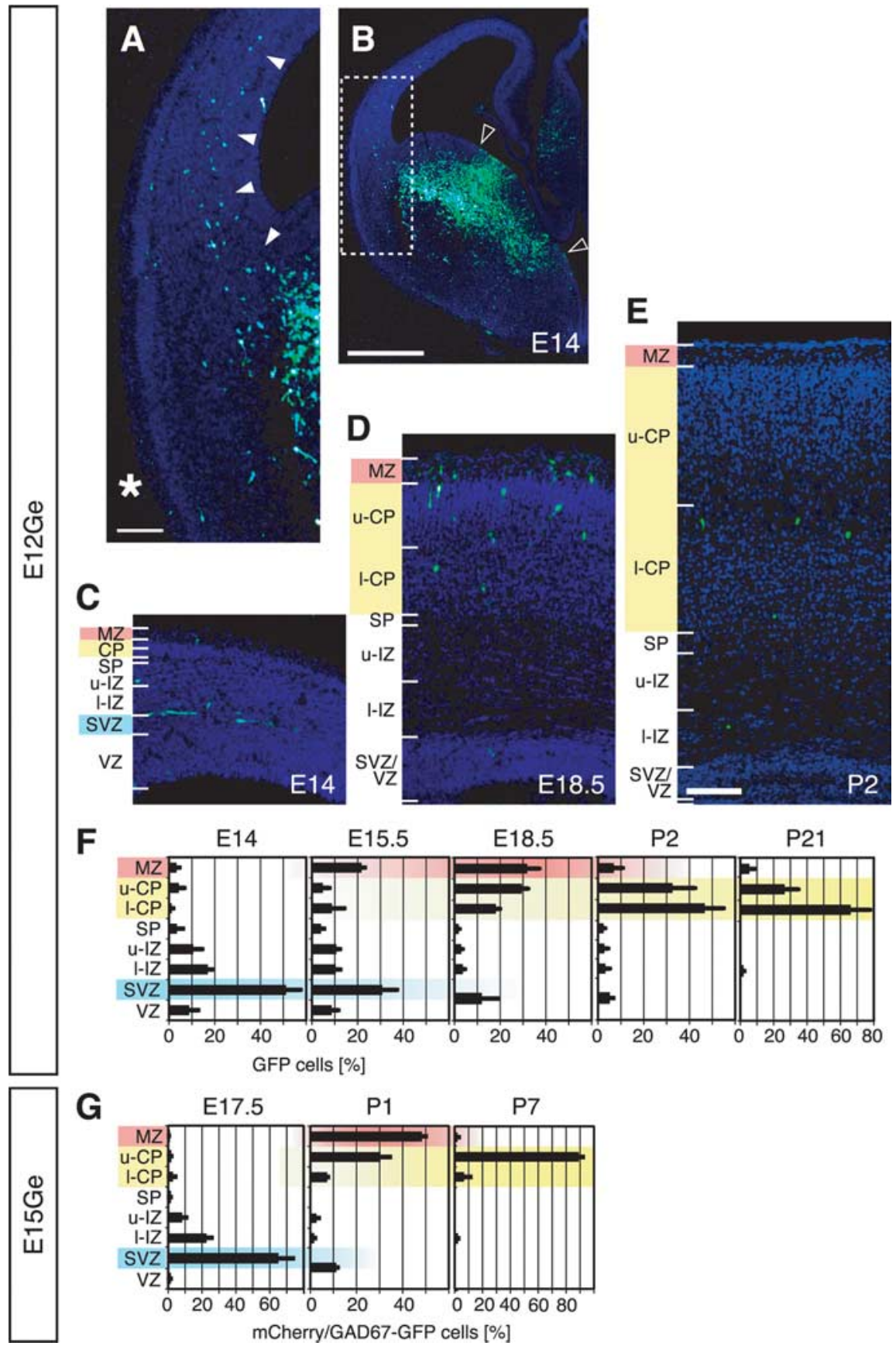

Figure 6. Transient accumulation of interneurons in the MZ. $\boldsymbol{A}$, Enlarged view of the boxed region in $\boldsymbol{B}$. GFP cells entered the cortex via the SVZ (arrowheads), not the MZ (asterisk). All sections were counterstained with DAPI (blue) to determine the cortical zones. $\boldsymbol{B}$, The distribution of GFP cells in the ipsilateral E12Ge:E14 forebrain. The region sandwiched between the open arrowheads is the presumptive region where Gfp plasmids were extensively transfected. $\boldsymbol{C}-\boldsymbol{E}$, The distribution of GFP cells in E12Ge:E14 (C), E12Ge:E18.5 (D), and E12Ge:P2 $(\boldsymbol{E})$ coronal sections. Dorsomedial is toward the right. $\boldsymbol{F}$, Quantification of the zonal distribution of labeled cells in E12Ge:E14 ( $n=273$ cells, 49 sections, 4 brains), E12Ge:E15.5 ( $n=222$ cells, 31 sections, 3 brains), E12Ge:E18.5 ( $n=659$ cells, 23 sections, 3 brains), E12Ge:P2 ( $n=174$ cells, 33 sections, 3 brains), and E12Ge:P21 ( $n=544$ cells, 178 sections, 5 brains) cortices (average \pm SEM). The abscissa indicates the proportion of labeled cells in each cortical zone. AtE14-E15.5, the cortical wall was subdivided into eight zones: $M Z$, upper $C P(\mathrm{U}-\mathrm{CP})$, lower $C P(\mathrm{I}-\mathrm{CP})$, subplate $(\mathrm{SP})$, upper intermediate zone (u-IZ), lower IZ (I-IZ), SVZ, and VZ. Because the border between the IZ and SVZ was obscure, the SVZ was defined as a zone with one-quarter thickness of the VZ. The SP was defined as a monolayer between the CP and the IZ. At both E18.5 and P2, SVZ and VZ were unified as one zone, SVZ/VZ. At P21, SP, IZ and SVZ/VZ were unified as one zone, white matter, whereas layers 1, 2-4, and $5 / 6$ were represented as $M Z, u-C P$, and $I-C P$ in the graph, respectively. These categories were made to simplify comparisons. $\mathbf{G}$, Same as $\boldsymbol{F}$, but for mCherry/GAD67-GFP double-labeled cells in E15Ge:E17.5 ( $n=250$ cells, 28 sections, 3 brains), E15Ge:P1 ( $n=$ 140 cells, 27 sections, 3 brains), and E15Ge:P7 ( $n=164$ cells, 24 sections, 3 brains) GAD67-GFP cortices. Scale bars: $\boldsymbol{A}, \boldsymbol{C}-\boldsymbol{E}, 100$ $\mu \mathrm{m} ; \boldsymbol{B}, 500 \mu \mathrm{m}$. rons frequently changed direction in an unpredictable manner as though they were wandering (Figs. 1, 2). These neurons remained within the MZ for a protracted period of time $(>30 \mathrm{~h}$ ) (Fig. 3). Theoretical analyses revealed that these behaviors could be modeled by a random walk (Fig. 4). We also found these interneurons born in the MGE entered the cortex via the SVZ path then moved to and accumulated in the $\mathrm{MZ}$ transiently before finally descending to the CP (Fig. 6). These results imply that MGE-derived cortical interneurons, once at the $\mathrm{MZ}$, are no longer regulated by guidance cues leading to random walk movement along a tangential plane (Fig. 8A).

\section{Technical considerations}

One might argue that nondirected, wandering behaviors may be artifacts caused by the in vitro culture. For example, it is possible that the molecular gradient needed to guide interneuron migration was disrupted in the cortical explant giving rise to wandering behavior of interneurons. We think it unlikely because (1) the size of the cortical explant used in this study ( $\sim 2 \times \sim 3 \mathrm{~mm}$ ) encompasses a large proportion of the cortex and the area for imaging was located in a small $(635 \times 635$ $\mu \mathrm{m}$ ) area within the explant (see Materials and Methods) and (2) some neurons that initially exhibited wandering-like behavior with repeated changes of the direction of migration moved in a specific direction at a later stage of recording (Fig. $1 D$; supplemental Fig. 5 and supplemental Movie 1, red arrowhead, available at www.jneurosci. org as supplemental material). It is also unlikely that the reduced motility shown by stationary cells or wandering behaviors was caused, for example, by phototoxicity as a result of long-periods of laser illumination because ( 1 ) in all preparations for time-lapse imaging, interneurons vigorously migrating in specific directions were intermingled among stationary and wandering cells (supplemental Movie 1, available at www.jneurosci.org as supplemental material) and (2) migrating neurons showed neither a reduction of motility nor enhancement of wandering behavior throughout the period of imaging as a whole (Fig. 1; supplemental Movie 1, available at www.jneurosci.org as supplemental material) (D. H. Tanaka and F. Murakami, unpublished observation). Moreover, we found common features between in vivo and in vitro preparations. (1) The morphologies of interneurons in time-lapse imaging were quite similar to those in our in vivo fixed preparations (Fig. $5 A-G)$. (2) The directionality of migrating 
cells in time-lapse imaging was also similar to the orientation of the cells' leading processes in fixed tissues (Fig. 5H). These findings support that in vivo behavior of interneurons are recapitulated in our in vitro preparations.

\section{Wandering behavior as a novel mode of} neuronal migration

Wandering behavior is a novel mode of neuronal migration distinct from previously reported modes including directed migration (Edmondson and Hatten, 1987; O'Rourke et al., 1992; Komuro and Rakic, 1995, 1998; Wichterle et al., 1997; Komuro et al., 2001; Nadarajah et al., 2001, 2002; Polleux et al., 2002; Ang et al., 2003; Tanaka et al., 2003, 2006; Yozu et al., 2005; Yokota et al., 2007) and multipolar migration (Tabata and Nakajima, 2003), although similar behaviors have been observed for isolated neurons in culture (see below). Our long-term tracking of individual neurons likely enabled us to discover the novel mode of migration.

Other than robustly migrating wandering and directed cells, there were also stationary cells (Figs. 1B,2). The causes of the behavioral differences between stationary and robustly migrating cells are unknown. It seems likely that migrating interneurons transiently become stationary because we have sometimes observed migrating cells followed by a stationary period and vice versa (supplemental Movie 1, orange arrowhead, available at www.jneurosci.org as supplemental material) (Tanaka and Murakami, unpublished observation).

\section{Tangential migration of MZ}

interneurons may be regulated by a

cell-autonomous mechanism

Conventionally, neuronal migration is thought to translocate neurons from one point to another via stereotyped pathways (Fig. $8 \mathrm{~B}$, left). In contrast, the MZ interneurons observed here exhibited a diverse range of behaviors and moved in an unpredictable manner (Fig. $8 B$, right). In theory, any migratory path could be explained if we assume spatiotemporally reg-

ulated expression of guidance cues and/or the neuron's responsiveness to these cues (Fig. $8 \mathrm{~B}$, left). However, the migrating behavior of individual neurons as observed here is too complex and diverse among different neurons to be explained by such mechanisms.

Accumulating evidence indicates that cortical interneuron diversity is attributable to differences in spatiotemporal origin, in the GEs, of the interneurons (Xu et al., 2004; Butt et al., 2005; Flames et al., 2007; Miyoshi et al., 2007; Wonders et al., 2008). A question then arises whether the diversity of interneuron behavior in this study may reflect the diversity of their origin. We do not think this likely because the mode of migration is interchangeable

\section{GFP Cre CXCR4}
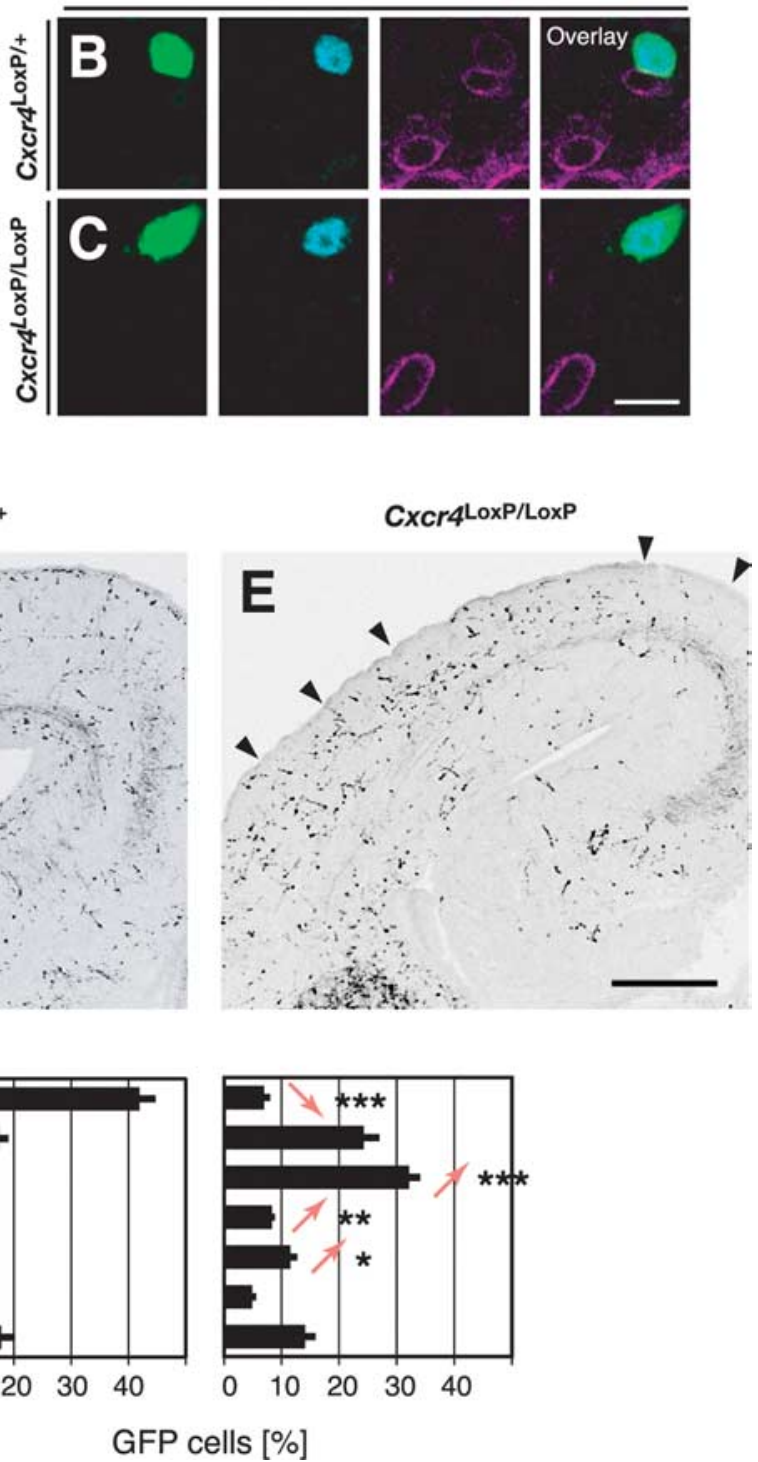

Figure 7. CXCR4 expressed in migrating interneurons labeled by GE-directed electroporation cell-autonomously functions for their accumulation in the MZ. $A$, Experimental paradigm used to examine the role of CXCR4 in migrating interneurons. $B, C, C X C R 4$ The expression of CXCR4 (magenta) in a GFP-labeled (green), (re-expressing (light blue) interneuron is reduced in CXCr4 loxP/loxP cortices $(\boldsymbol{C})$ compared with that in $C x c r 4^{10 x P /+}$ cortices (B). D, E, The distribution of GFP cells $6 \mathrm{~d}$ after electroporation (E18.5) in right. $F$, Quantitative analysis of the distribution of GFP cells within the cortex $6 \mathrm{~d}$ after electroporation (E18.5) in $\mathrm{XCr}^{\mathrm{loxP} /+}$ (left; in each cortical zone. Statistical analysis was done between genotypes in each zone. ${ }^{* * *} p=0.0009 ;{ }^{* *} p=0.003 ;{ }^{*} p<0.016$; Mann-Whitney U test. Scale bars: $\boldsymbol{B}, \boldsymbol{C}, 10 \mu \mathrm{m} ; \boldsymbol{D}, \boldsymbol{E}, 300 \mu \mathrm{m}$. SP, Subplate; IZ, intermediate zone.

for individual neurons (supplemental Movie 1, orange arrowhead, and supplemental Fig. 5, available at www.jneurosci.org as supplemental material) (Tanaka and Murakami, unpublished observation). Furthermore, more than half of migrating cells in the MZ showed wandering behavior both for E12.5 and E15.5 electroporated samples (Fig. 2), suggesting that migration in a nondirected manner is perhaps a general behavioral pattern that could be taken by each interneuron subtype. An alternative and more intriguing possibility is that these behaviors are not under the control of external guidance cues; MZ interneurons may be able to change the direction of migration cell-autonomously in the absence of guidance cues (Fig. $8 B$, right). The finding that 


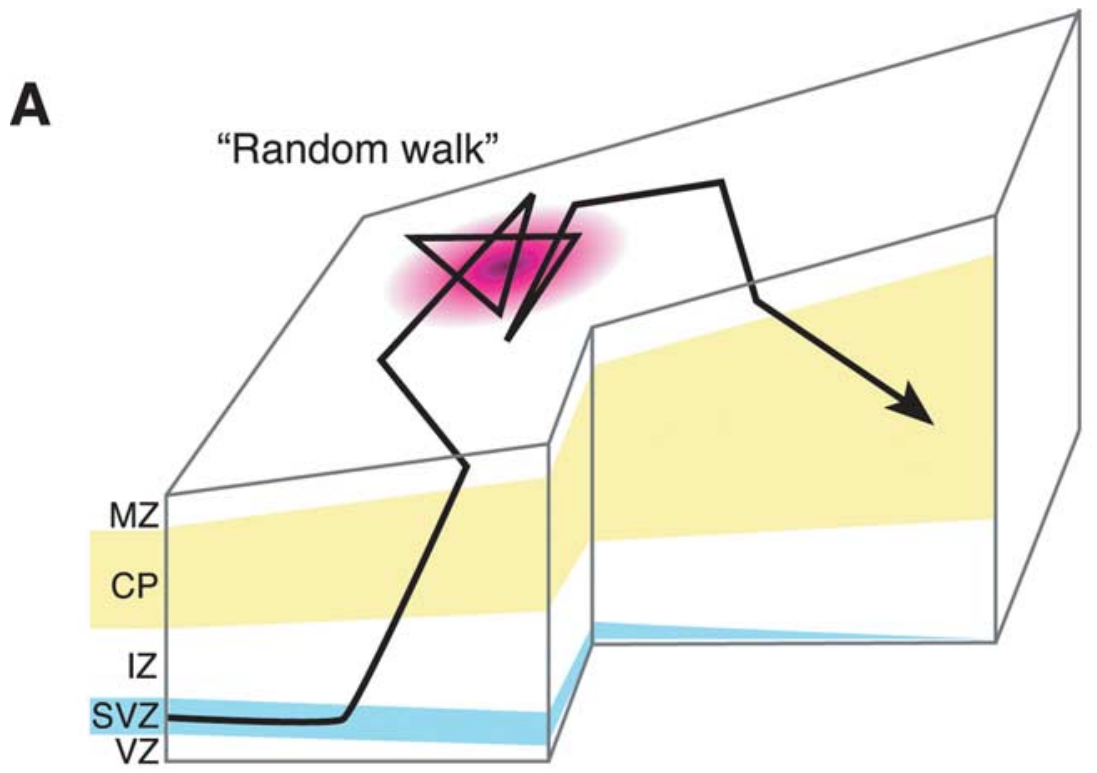

B

\section{Conventional view}
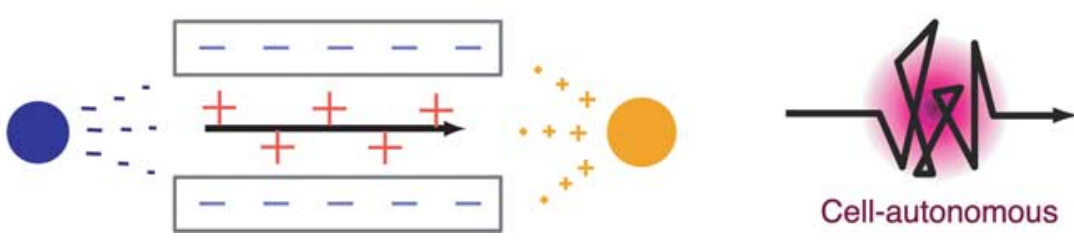

Figure 8. Models of intracortical migration pathways and underlying mechanisms for MGE-derived interneurons. A, A model of the migratory pathway for interneurons within the developing cerebral cortex. Interneurons derived from the MGE initially enter the $C P$ from the SVZ, pass through it, reach the $M Z$, move in a random walk manner, and then migrate back to and remain in the CP. Some interneurons in the SVZ may exhibit ventricle-directed migration in the VZ (Nadarajah et al., 2002) before they migrate toward the MZ, which could not be detected in the present study. IZ, Intermediate zone. $\boldsymbol{B}$, Models of migratory mechanisms for random walk behavior. A conventional view of neuronal migration argues neurons translocate from one point to another via stereotyped pathways (left). The direction of migration can be regulated by spatiotemporally regulating the expression of guidance cues (orange plus, chemoattractant; red plus, contact attractant; dark blue minus, chemorepellent; light blue minus, contact repellent) and by regulating the neurons' responses to these cues. In contrast, the migratory pathways observed here were diverse and unpredictable (right). These behaviors cannot be fully explained by the conventional model. Instead, it is likely regulated by guidance cue-independent, cell-autonomous mechanisms.

migrating cells moved in all directions (Fig. 5H) is consistent with this idea.

It seems likely that intrinsic mechanisms affecting interneuron migration has manifested in the $\mathrm{MZ}$, possibly in response to the absence of guidance cues. Indeed, dissociated cortical interneurons plated on a uniform substrate, namely glial feeder cells, exhibited diverse behaviors where many spontaneously changed migration direction, similar to this study (N. Inamura and $\mathrm{Mu}-$ rakami, unpublished observation). Similar observations were reported for cortical cells plated on a glial feeder layer (Hayashi et al., 2003), anterior SVZ-derived cells in collagen gels (Ward et al., 2005), and cerebellar granule cells on laminin (Yacubova and Komuro, 2002). As such, we postulate that the wandering behavior of individual neurons and the behavioral diversity as reported here may not be normally observed because external guidance cues override the migrating neurons' innate migrating properties. Although the molecular basis for such a cell-autonomous mechanism remains unknown, one intriguing possibility is that a spontaneous and transient elevation of intracellular $\mathrm{Ca}^{2+}$ levels $\left(\left[\mathrm{Ca}^{2+}\right]_{\mathrm{i}}\right)$ in $\mathrm{MZ}$ interneurons induces direction change. Spontaneous and transient elevations of $\left[\mathrm{Ca}^{2+}\right]_{\mathrm{i}}$ has been observed in non-CajalRetzius cells, which probably include GABAergic interneurons, in both embryonic and neonatal MZ (Schwartz et al., 1998). Furthermore, in cerebellar granule cells, $\left[\mathrm{Ca}^{2+}\right]_{i}$ elevation in the somata is sufficient to cause the reversal of soma translocation (Guan et al., 2007). Additional experiments monitoring and manipulating the $\left[\mathrm{Ca}^{2+}\right]_{\mathrm{i}}$ in $\mathrm{MZ}$ migrating interneurons are needed to establish causality.

Random walk in the developing cortex Fishell et al. (1993) have observed that cortical progenitors in the $\mathrm{VZ}$ also migrate in many directions and found their movement can be described as a random walk or diffusion mode by using the same theoretical analysis as described above (Gruler and Bultmann, 1984) (Fig. 4). Although theoretical analyses have not been performed, they also observed large numbers of randomly oriented TUJ1-positive immature neurons in the cortical VZ (Neyt et al., 1997). Consistent with this, GAD67GFP cells in the ventricular zone showed multidirectional migration similar to that observed for MZ interneurons (Tanaka et al., 2006). These findings raise the possibility that movement of cells in a diffusion mode is a widespread phenomenon in the developing cortex.

\section{Tangential dispersion of interneurons in the MZ}

It has remained unknown how cortical interneurons originating from restricted regions in the basal forebrain eventually distribute almost evenly in the entire cortical area. Previously, we proposed that the dispersion of cortical interneurons takes place in the MZ based on 1,1'-dioctadecyl-3,3,3',3' -tetramethylindodicarbocyanine (DiD) labeling in vivo (Tanaka et al., 2006). However, the pathway for the dispersion has remained obscure because we could not observe the process of dispersion directly. In this study, we demonstrated that interneurons continue migration for a few days within the $\mathrm{MZ}$ and the movement of the interneurons in the MZ can be described as a diffusion mode (Gruler and Bultmann, 1984) (Fig. 4). This is consistent with the behavior of individual neurons repeatedly changing their direction of migration in an unpredictable manner (Figs. 1, 2). Moreover, the fact that DiD-labeled neurons were oriented in many directions disregard of the DiD injection site (Tanaka et al., 2006) (Tanaka, K. Maekawa, and Murakami, unpublished observation) supports the idea that these neurons undergo a random walk movement. Considering that diffusion is known as a process resulting from random motion of molecules by which there is a net flow of matter from a region of high concentration to a region of 
low concentration, these findings indicate that spread of cortical interneurons in the $\mathrm{MZ}$ takes place as a result of a diffusion, leading to their even distribution within the cortex. This is consistent with the results of previous studies that showed interneuron migration disruption in the $\mathrm{MZ}$ causes changes in the distribution of interneurons in the mature cortex (Li et al., 2008; Lopez-Bendito et al., 2008).

\section{Lingering of interneurons within the MZ}

Long-time lingering of interneurons within the MZ suggests that the $\mathrm{MZ}$ is used for migrating interneurons not only as a location for dispersion but also as a waiting lounge. Interestingly, the diverse behaviors of interneurons in the MZ lasted $>1 \mathrm{~d}$ (Fig. 3 ). Our results also indicated that CXCL12/CXCR4 signaling contributed to this lingering (Fig. 7; supplemental Figs. 2-4, available at www.jneurosci.org as supplemental material). Considering that many interneurons in the MZ finally migrate down to the CP (Wichterle et al., 2001; Ang et al., 2003; Tanaka et al., 2003; 2006; Hevner et al., 2004) (Fig. 6), MZ interneurons might be waiting for the arrival of signals required for subsequent migration to the $\mathrm{CP}$.

In conclusion, we have discovered a novel moving behavior for cortical interneurons. A large fraction of them repeatedly changed their direction of migration during the course of tangential migration in the MZ, a behavior that cannot be fully explained by the neuron's response to external guidance cues. Theoretical analysis indicated that $\mathrm{MZ}$ interneurons move in a diffusion mode. This may, in turn, contribute to the interneuron dispersion throughout the cortex.

\section{References}

Ang ES Jr, Haydar TF, Gluncic V, Rakic P (2003) Four-dimensional migratory coordinates of GABAergic interneurons in the developing mouse cortex. J Neurosci 23:5805-5815.

Ara T, Tokoyoda K, Sugiyama T, Egawa T, Kawabata K, Nagasawa T (2003) Long-term hematopoietic stem cells require stromal cell-derived factor-1 for colonizing bone marrow during ontogeny. Immunity 19:257-267.

Berg HC (1993) Random walks in biology. Princeton, NJ: Princeton UP.

Bloch-Gallego E, Causeret F, Ezan F, Backer S, Hidalgo-Sanchez M (2005) Development of precerebellar nuclei: instructive factors and intracellular mediators in neuronal migration, survival and axon pathfinding. Brain Res Brain Res Rev 49:253-266.

Borrell V, Marín O (2006) Meninges control tangential migration of hemderived Cajal-Retzius cells via CXCL12/CXCR4 signaling. Nat Neurosci 9:1284-1293.

Brose K, Tessier-Lavigne M (2000) Slit proteins: key regulators of axon guidance, axonal branching, and cell migration. Curr Opin Neurobiol 10:95-102.

Butt SJ, Fuccillo M, Nery S, Noctor S, Kriegstein A, Corbin JG, Fishell G (2005) The temporal and spatial origins of cortical interneurons predict their physiological subtype. Neuron 48:591-604.

Cepko CL (1999) The roles of intrinsic and extrinsic cues and bHLH genes in the determination of retinal cell fates. Curr Opin Neurobiol 9:37-46.

Edmondson JC, Hatten ME (1987) Glial-guided granule neuron migration in vitro: a high-resolution time-lapse video microscopic study. J Neurosci 7:1928-1934

Fishell G, Mason CA, Hatten ME (1993) Dispersion of neural progenitors within the germinal zones of the forebrain. Nature 362:636-638.

Flames N, Pla R, Gelman DM, Rubenstein JL, Puelles L, Marín O (2007) Delineation of multiple subpallial progenitor domains by the combinatorial expression of transcriptional codes. J Neurosci 27:9682-9695.

Gleeson JG, Walsh CA (2000) Neuronal migration disorders: from genetic diseases to developmental mechanisms. Trends Neurosci 23:352-359.

Gruler H, Bultmann BD (1984) Analysis of cell movement. Blood Cells 10:61-77.

Guan CB, Xu HT, Jin M, Yuan XB, Poo MM (2007) Long-range Ca2+ signaling from growth cone to soma mediates reversal of neuronal migration induced by slit-2. Cell 129:385-395.
Hatanaka Y, Hisanaga S, Heizmann CW, Murakami F (2004) Distinct migratory behavior of early- and late-born neurons derived from the cortical ventricular zone. J Comp Neurol 479:1-14.

Hayashi K, Kawai-Hirai R, Harada A, Takata K (2003) Inhibitory neurons from fetal rat cerebral cortex exert delayed axon formation and active migration in vitro. J Cell Sci 116:4419-4428.

Hevner RF, Daza RA, Englund C, Kohtz J, Fink A (2004) Postnatal shifts of interneuron position in the neocortex of normal and reeler mice: evidence for inward radial migration. Neuroscience 124:605-618.

Jessell TM (2000) Neuronal specification in the spinal cord: inductive signals and transcriptional codes. Nat Rev Genet 1:20-29.

Kawamoto S, Niwa H, Tashiro F, Sano S, Kondoh G, Takeda J, Tabayashi K, Miyazaki J (2000) A novel reporter mouse strain that expresses enhanced green fluorescent protein upon Cre-mediated recombination. FEBS Lett 470:263-268.

Komuro H, Rakic P (1995) Dynamics of granule cell migration: a confocal microscopic study in acute cerebellar slice preparations. J Neurosci 15:1110-1120.

Komuro H, Rakic P (1998) Distinct modes of neuronal migration in different domains of developing cerebellar cortex. J Neurosci 18:1478-1490.

Komuro H, Yacubova E, Rakic P (2001) Mode and tempo of tangential cell migration in the cerebellar external granular layer. J Neurosci 21:527-540.

Lambert de Rouvroit C, Goffinet AM (2001) Neuronal migration. Mech Dev 105:47-56.

Li G, Adesnik H, Li J, Long J, Nicoll RA, Rubenstein JL, Pleasure SJ (2008) Regional distribution of cortical interneurons and development of inhibitory tone are regulated by Cxcl12/Cxcr4 signaling. J Neurosci 28:1085-1098.

Liapi A, Pritchett J, Jones O, Fujii N, Parnavelas JG, Nadarajah B (2008) Stromal-derived factor 1 signalling regulates radial and tangential migration in the developing cerebral cortex. Dev Neurosci 30:117-131.

Lopez-Bendito G, Sanchez-Alcaniz JA, Pla R, Borrell V, Pico E, Valdeolmillos M, Marín O (2008) Chemokine signaling controls intracortical migration and final distribution of GABAergic interneurons. J Neurosci 28:1613-1624.

Marín O, Rubenstein JL (2003) Cell migration in the forebrain. Annu Rev Neurosci 26:441-483.

Marquardt T, Gruss P (2002) Generating neuronal diversity in the retina: one for nearly all. Trends Neurosci 25:32-38.

Ming GL, Wong ST, Henley J, Yuan XB, Song HJ, Spitzer NC, Poo MM (2002) Adaptation in the chemotactic guidance of nerve growth cones. Nature 417:411-418.

Miyoshi G, Butt SJ, Takebayashi H, Fishell G (2007) Physiologically distinct temporal cohorts of cortical interneurons arise from telencephalic Olig2expressing precursors. J Neurosci 27:7786-7798.

Nadarajah B, Brunstrom JE, Grutzendler J, Wong RO, Pearlman AL (2001) Two modes of radial migration in early development of the cerebral cortex. Nat Neurosci 4:143-150.

Nadarajah B, Alifragis P, Wong RO, Parnavelas JG (2002) Ventricledirected migration in the developing cerebral cortex. Nat Neurosci 5:218-224.

Neyt C, Welch M, Langston A, Kohtz J, Fishell G (1997) A short-range signal restricts cell movement between telencephalic proliferative zones. J Neurosci 17:9194-9203.

Niwa H, Yamamura K, Miyazaki J (1991) Efficient selection for highexpression transfectants with a novel eukaryotic vector. Gene 108:193-199.

O’Rourke NA, Dailey ME, Smith SJ, McConnell SK (1992) Diverse migratory pathways in the developing cerebral cortex. Science 258:299-302.

Paredes MF, Li G, Berger O, Baraban SC, Pleasure SJ (2006) Stromalderived factor-1 (CXCL12) regulates laminar position of Cajal-Retzius cells in normal and dysplastic brains. J Neurosci 26:9404-9412.

Park HT, Wu J, Rao Y (2002) Molecular control of neuronal migration. Bioessays 24:821-827.

Polleux F, Whitford KL, Dijkhuizen PA, Vitalis T, Ghosh A (2002) Control of cortical interneuron migration by neurotrophins and PI3-kinase signaling. Development 129:3147-3160.

Rice DS, Curran T (2001) Role of the reelin signaling pathway in central nervous system development. Annu Rev Neurosci 24:1005-1039.

Ross ME, Walsh CA (2001) Human brain malformations and their lessons for neuronal migration. Annu Rev Neurosci 24:1041-1070.

Schwartz TH, Rabinowitz D, Unni V, Kumar VS, Smetters DK, Tsiola A, 
Yuste R (1998) Networks of coactive neurons in developing layer 1. Neuron 20:541-552.

Shaner NC, Campbell RE, Steinbach PA, Giepmans BN, Palmer AE, Tsien RY (2004) Improved monomeric red, orange and yellow fluorescent proteins derived from Discosoma sp. red fluorescent protein. Nat Biotechnol 22:1567-1572.

Shirasaki R, Pfaff SL (2002) Transcriptional codes and the control of neuronal identity. Annu Rev Neurosci 25:251-281.

Stumm RK, Zhou C, Ara T, Lazarini F, Dubois-Dalcq M, Nagasawa T, Hollt $\mathrm{V}$, Schulz S (2003) CXCR4 regulates interneuron migration in the developing neocortex. J Neurosci 23:5123-5130.

Tabata H, Nakajima K (2003) Multipolar migration: the third mode of radial neuronal migration in the developing cerebral cortex. J Neurosci 23:9996-10001.

Tamagnone L, Comoglio PM (2004) To move or not to move? Semaphorin signalling in cell migration. EMBO Rep 5:356-361.

Tamamaki N, Yanagawa Y, Tomioka R, Miyazaki J, Obata K, Kaneko T (2003) Green fluorescent protein expression and colocalization with calretinin, parvalbumin, and somatostatin in the GAD67-GFP knock-in mouse. J Comp Neurol 467:60-79.

Tanaka D, Nakaya Y, Yanagawa Y, Obata K, Murakami F (2003) Multimodal tangential migration of neocortical GABAergic neurons independent of GPI-anchored proteins. Development 130:5803-5813.

Tanaka DH, Maekawa K, Yanagawa Y, Obata K, Murakami F (2006) Multidirectional and multizonal tangential migration of GABAergic interneurons in the developing cerebral cortex. Development 133:2167-2176.

ten Donkelaar HJ, Lammens M, Wesseling P, Thijssen HO, Renier WO (2003) Development and developmental disorders of the human cerebellum. J Neurol 250:1025-1036.

Tiveron MC, Rossel M, Moepps B, Zhang YL, Seidenfaden R, Favor J, Konig $\mathrm{N}$, Cremer H (2006) Molecular interaction between projection neuron precursors and invading interneurons via stromal-derived factor 1
(CXCL12)/CXCR4 signaling in the cortical subventricular zone/intermediate zone. J Neurosci 26:13273-13278.

Tokoyoda K, Egawa T, Sugiyama T, Choi BI, Nagasawa T (2004) Cellular niches controlling B lymphocyte behavior within bone marrow during development. Immunity 20:707-718.

Walsh CA (2000) Genetics of neuronal migration in the cerebral cortex. Ment Retard Dev Disabil Res Rev 6:34-40.

Ward ME, Jiang H, Rao Y (2005) Regulated formation and selection of neuronal processes underlie directional guidance of neuronal migration. Mol Cell Neurosci 30:378-387.

Wichterle H, Garcia-Verdugo JM, Alvarez-Buylla A (1997) Direct evidence for homotypic, glia-independent neuronal migration. Neuron 18:779-791.

Wichterle H, Turnbull DH, Nery S, Fishell G, Alvarez-Buylla A (2001) In utero fate mapping reveals distinct migratory pathways and fates of neurons born in the mammalian basal forebrain. Development 128:3759-3771.

Wingate RJ (2001) The rhombic lip and early cerebellar development. Curr Opin Neurobiol 11:82-88.

Wonders CP, Taylor L, Welagen J, Mbata IC, Xiang JZ, Anderson SA (2008) A spatial bias for the origins of interneuron subgroups within the medial ganglionic eminence. Dev Biol 314:127-136.

Xu Q, Cobos I, De La Cruz E, Rubenstein JL, Anderson SA (2004) Origins of cortical interneuron subtypes. J Neurosci 24:2612-2622.

Yacubova E, Komuro H (2002) Intrinsic program for migration of cerebellar granule cells in vitro. J Neurosci 22:5966-5981.

Yokota Y, Gashghaei T, Han C, Watson H, Campbell KJ, Anton ES (2007) Radial glial dependent and independent dynamics of interneuronal migration in the developing cerebral cortex. PLoS ONE 2:e794.

Yozu M, Tabata H, Nakajima K (2005) The caudal migratory stream: a novel migratory stream of interneurons derived from the caudal ganglionic eminence in the developing mouse forebrain. J Neurosci 25:72687277. 